\title{
Nanofer ZVI: Morphology, Particle Characteristics, Kinetics, and Applications
}

\author{
Mahmoud M. Eglal and Amruthur S. Ramamurthy \\ Department of Building Civil and Environmental Engineering, Concordia University, 1455 de Maisonneuve Boulevard West, Montréal, \\ QC, Canada H3G $1 M 8$ \\ Correspondence should be addressed to Mahmoud M. Eglal; alsbaae1@gmail.com
}

Received 17 December 2013; Accepted 11 February 2014; Published 7 April 2014

Academic Editor: William W. Yu

Copyright (C) 2014 M. M. Eglal and A. S. Ramamurthy. This is an open access article distributed under the Creative Commons Attribution License, which permits unrestricted use, distribution, and reproduction in any medium, provided the original work is properly cited.

\begin{abstract}
Nanofer zerovalent iron (nanofer ZVI) is a new and innovative nanomaterial capable of removing organic as well as inorganic contaminants in water. It displays a decrease in agglomeration, when it is coated with tetraethyl orthosilicate (TEOS). TEOS imparts an increase in reactivity and stability to nanofer ZVI. Characteristics of nanofer ZVI were determined using scanning electron microscope/electron dispersive spectroscope (SEM/EDS), transmission electron microscope (TEM), and X-ray diffraction (XRD). Nanoparticle size varied from 20 to $100 \mathrm{~nm}$ and its surface area was in the range of $25-30 \mathrm{~m}^{2} \mathrm{~g}^{-1}$. The present study examined its structure before and after kinetic experiments. Kinetic experiments indicated that adsorption of heavy metals [Pb (II), Cd (II), and $\mathrm{Cu}$ (II)] and TCE is very rapid during the initial step which is followed by a much slower second step. Removal rates of $99.7 \%$ for $\mathrm{Pb}$ (II), 99.2\% for Cd (II), 99.9\% for Cu (II), and 99.9\% for TCE were achieved in less than 180 minutes. Lagergren models (LM), liquid film diffusion model (LFDM), and interparticle diffusion model (IDM) were used to understand the removal mechanism associated with nanofer ZVI. In this study, interactions of nanofer ZVI with individual metals as well as TCE are examined.
\end{abstract}

\section{Introduction}

It is almost a decade since the zerovalent iron nanoparticle application was engineered. The application of conventional nanoparticles to remove organic and inorganic contaminants from water has received considerable attention. The new nanofer ZVI is the third generation of iron nanoparticles (nZVI) produced in 2012. It is highly applicable in the oxidation-reduction technologies of water remediation $[1,2]$. The oxidation of organic contaminants produces hydroxyls, superoxides, and hydrogen gas. They play a significant role in the degradation of organic contaminants [3-6]. Iron particle disassociation and metal adsorption by nanoparticles are the mechanisms by which nZVI removes inorganics. The study of nanofer ZVI to remove organic and inorganic contaminants in water is crucial.

The life time and agglomeration of particles are the main hurdles for the use of the conventional nZVI for the remediation of contaminated water. The particle life time varies from 2 hours to a few days. Further, in some cases, the particle agglomeration can be even shorter than 2 hrs. In the last decade, extensive research was focused on enhancing the mobility and dispersion of particles by adding transitional metals or coating the nZVI particles with silicon-based materials. The NANOIRON Company produced nanofer ZVI [7] by coating the conventional nZVI particles with tetraethyl orthosilicate (TEOS). Other types of coatings such as carboxymethyl cellulose (CMC) and polyacrylic acid-stabilized coatings are also reported to be effective in increasing the stability of nZVI while passing through soil, when nanoparticles are injected into the soil to reduce groundwater contamination $[8,9]$.

Due to the presence of the coating, the nanofer ZVI is stable, transportable, reactive, and air-stable. Hence, it is much easier and safer to store, handle, transport, and process compared to other nonstabilized conventional nZVI. It maintains its extreme reactivity in the presence of reducible pollutants in the water environment [7]. As such, the (new) nanofer ZVI is suitable for direct application to remove contaminants from polluted water as well as for the preparation 
of slurries injected for in situ groundwater remediation. Its advantages include the stabilization of particles by the thin layer which inhibits particles from rapid oxidation when they are in contact with air. Also, it maintains its high reactivity in water, in spite of surface stabilization with silica coating. Further, this coating enables it to be free of pyrophoric properties and permits easy handling. Hence, it results in much lower packaging and transportation costs compared to other conventional nZVI [10]. Only few feasible procedures have been suggested in literature to dispose the spent nanoparticle used remediation processes. For instance, Karn et al. [11] have suggested that the spent nanoparticle are susceptible to be taken up by microorganism. US EPA [12] has also suggested possibility of biomagnification of nanoparticles as intermediate for eventual disposal. After completing the treatment at the point source, Nowack [13] has suggested that the residual water left should be pumped out to the surface and separate the nZVI containing the contaminants using filters.

The adsorption or reaction kinetics of nanoparticle system in the presence of contaminated water must be studied to determine the appropriate design that results in the extended lifetime and reactivity of particles $[14,15]$. Recently, several studies have investigated the use of nZVI that were coated by other metals such as Pd and Ni which impart higher stability and reactivity to nZVI particles. For instance, Greenlee et al. [16] studied the kinetic adsorption as well as the oxidation of TCE by bimetallic nanoparticles (Ni-Fe nZVI) using the results based on SEM/EDS data analysis. They found that bimetallic nanoparticles have increased reactivity well above the conventional nZVI. Also, it was noticed that nZVI got primarily oxidized to iron oxide-hydroxide (lepidocrocite) in the presence of oxygenated water. Li et al. [17] have examined the injection of bimetallic nanoparticles ( $\mathrm{Pd}-\mathrm{Fe}$ nZVI) to a sand aquifer that was contaminated by TCE. They found that the nanoparticles injected to the aquifer did not reach the target area due to their reactivity with the soil. Both Environmental Protection Agency (EPA, 2012) and the Office of Solid Waste and Emergency Response (OSWER, 2012) investigated the scope of remedying several sites contaminated with organic and inorganic contaminants using different nZVI. They treated almost 90 percent of sites by bimetallic nanoscale particles (BNP) produced by Lehigh University (USA) and the conventional nZVI. 95\% of target contaminants were organics such as trichloroethylene (TCE), polychlorinated biphenyls (PCB), 1,1,1-trichloroethane (TCA), and vinyl chloride (VC). In most cases, a second injection of nZVI was needed to reach the desired contaminant concentration level.

Little is known about the reaction kinetics and products formed during metal adsorption or oxidation-reduction by nZVI, especially the coated form. Even fewer studies have investigated TCE dechlorination by coated nZVI with metal or different polymers $[5,16,17]$. However, only few details of the nanoparticle distribution and reaction kinetics have been provided. The pathways of TCE dechlorination and metal removal by coated nZVI have not been explored.

Several methods such as precipitation, electrochemical reduction, adsorption, ion exchange, solvent extraction, and nanofiltration are used to remove heavy metals $(\mathrm{Cu}, \mathrm{Pb}$, and $\mathrm{Cd}$ ) from groundwater. These operations are expensive, often generate excessive sludge, and lead to operational problems [20]. Heavy metals in groundwater can be removed more efficiently using nanomaterials. Considerable attention is currently paid to study the use of nZVI to remove heavy metals from groundwater [20]. The mechanisms of heavy metal removal using nZVI depend on the standard redox potential $\left(E^{0}\right)$ of the metal contaminant. Metals that have an $E^{0}$ which is more negative than or similar to that of $\mathrm{Fe}^{0}$ (e.g., Cd) are removed by adsorption to the iron hydroxide shell. On the other hand, metals with $E^{0}$ which is much more positive than $\mathrm{Fe}^{0}$ (e.g., $\mathrm{Cu}$ ) are preferentially removed by reduction and precipitation. Metals for which $E^{0}$ is only slightly more positive than that for $\mathrm{Fe}^{0}$ (e.g., $\mathrm{Pb}$ ) can be removed by reduction and adsorption [20]. O'Carroll et al. [21] rightly stated that oxidation and coprecipitation involved in heavy metal removal depend on the prevailing chemical conditions ( $\mathrm{pH}$, initial concentration, and speciation of contaminant metals). In most cases, addition of nZVI to the aqueous solution increases $\mathrm{pH}$ due to the generation of $\mathrm{OH}^{-}$resulting in the immobilization of metal by precipitation as the hydroxide [21]. This also suggests that other metal contaminants with more negative redox potential than $\mathrm{Fe}^{0}$ may be removed by adsorption and precipitation on the $\mathrm{nZVI}$ surface.

Recently, Rangsivek and Jekel [22] studied the removal of $\mathrm{Cu}$ II by macroscale ZVI and showed that a substantial portion of $\mathrm{Cu}$ II is reduced and transformed to insoluble form of $\mathrm{Cu}$ and $\mathrm{Cu}_{2} \mathrm{O}$. More recently, Ayob et al. [23] studied the adsorption of $\mathrm{Cu}$ II by nZVI coated by carboxymethyl cellulose (CMC-nZVI) and found that the removal efficiency is highly $\mathrm{pH}$-dependent. The removal of $\mathrm{Pb}$ II by bimetallic nanoparticles $(\mathrm{Ni} / \mathrm{Fe})$ has also been reported by Saberi [24]. O'Carroll et al. [21] have indicated that only few studies have investigated the adsorption kinetic of metal removal by nZVI. They also suggested that more research is needed to investigate the adsorption mechanism and kinetics associated with other metals that can be removed by nZVI.

In the present study, surface morphology and surface chemistry of the new nanofer ZVI were determined using spectroscopic image data (SEM/EDS, TEM, and XRD). The surface area of nanofer ZVI was obtained using the BET procedure. The kinetics of adsorption of heavy metals ( $(\mathrm{Pb}$ (II), Cu (II), and Cd (II)) and dechlorination of TCE present in polluted water by the new nanofer ZVI were investigated. To achieve this goal, the experimental data were collected and the results were used to validate the Lagergren model as well as the liquid diffusion model. The study also scrutinizes the reaction pathways of the removal of metals and TCE by the new nanofer ZVI from contaminated water.

\section{Materials and Methods}

2.1. Chemicals. Details related to different chemical solutions used in the study are presented in Tables 1 and 2 . All chemicals supplied by Fisher Scientific were classed as pure grade (99.9\%). 
TABLE 1: Selected organic and inorganic chemicals used in the study.

\begin{tabular}{ccc}
\hline Reagent & Formula & Source \\
\hline Inorganic & & \\
$\mathrm{Cu}(\mathrm{II})$ & $\mathrm{CuCl}_{2}$ & Fisher \\
$\mathrm{Cd}(\mathrm{II})$ & $\mathrm{CdCl}_{2}$ & Fisher \\
$\mathrm{Pb}(\mathrm{II})$ & $\mathrm{Pb}(\mathrm{II}) \mathrm{Cl}_{2}$ & Fisher \\
Organic & & \\
TCE & $\mathrm{C}_{2} \mathrm{HCl}_{3}$ & Fisher \\
$\mathrm{PVP}$ & $\left(\mathrm{C}_{6} \mathrm{H}_{9} \mathrm{NO}_{n}\right.$ & Sigma Aldrich \\
TEOS & $\mathrm{SiC}_{8} \mathrm{H}_{20} \mathrm{O}_{4}$ & Sigma Aldrich \\
\hline
\end{tabular}

TABLE 2: Metal ion characteristics [18, 19].

\begin{tabular}{lccc}
\hline Characteristics & \multicolumn{3}{c}{ Metals } \\
& $\mathrm{Cu}(\mathrm{II})$ & $\mathrm{Pb}(\mathrm{II})$ & $\mathrm{Cd}(\mathrm{II})$ \\
\hline Hydrated radius $(\AA)$ & 4.19 & 4.01 & 4.26 \\
Ionic radius (A) & 0.72 & 1.2 & 0.97 \\
Electronegativity & 1.8 & 1.6 & 1.5 \\
Polarization & 6.1 & 6.8 & 7.2 \\
Electron configuration & $4 \mathrm{~s} 3 \mathrm{~d}$ & $6 \mathrm{~s} 4 \mathrm{f} 5 \mathrm{~d} 6 \mathrm{p}$ & $5 \mathrm{~s} 4 \mathrm{~d}$ \\
& $1 \mathrm{~B}$ & $4 \mathrm{~A}$ & $2 \mathrm{~B}$ \\
\hline
\end{tabular}

2.2. ZVI Nanoparticles. The iron suspension characterized and modified in this study was supplied by the Czech company, NANOIRON ltd. The material was developed to overcome the uncoated nanofer 25 which was produced via a dry reduction of iron oxide. However, the coated nanofer $\mathrm{ZVI}$ is a new innovative material produced by impregnating the iron oxide with polyvinylpyrrolidone (PVP) and socked and coated with tetraethyl orthosilicate (TEOS). Lenka et al. [7] provide more information about these two products. Deionized water was used in all experiments.

\subsection{Surface Morphology and Particle Characteristics}

2.3.1. Transmission Electron Microscope Images. Images of the nanofer ZVI particles were recorded with the JOEL 2000 FX Transmission microscope (JOEL ltd, Japan). The samples deposited on the top of the sample holder by adding two to three droplets of nanofer ZVI onto the carbon film. The sample holder was cleaned by air to removal unglued particles. Using the TEM, the particle structure was examined by passing beam of electrons through the specimen. The transmission of the electron beam depends on the properties such as density and composition of materials. The image appeared as a shadow of the specimen on the screen. The best image showing the particle characteristics was selected from the data collected.

2.3.2. Scanning Electron Microscope/Electron Dispersive Microscope. The SEM was operated using the Hitachi S3400N equipped with the EDS system. The samples were placed on top of the sample holder using carbon duck liquid. The operating voltage was $15 \mathrm{kV}$. The energy dispersive $\mathrm{X}$-ray spectroscope (EDS) was conditioned at $55 \mathrm{kV}$, dead time $35 \%$, and a stage-working distance between 9.8 and 10 .

2.3.3. X-Ray Diffractometer. The Philips X pert Pro multipurpose X-ray diffractometer was used with parafocusing Bragg-Brentano geometry and CuKa radiation column $(\lambda=$ $1.5418 \AA, V=40 \mathrm{kV}$, and $i=30 \mathrm{~mA}$ ). The particles were placed in a glass holder and scanned from $20^{\circ}$ to $75^{\circ}$. This scan range covered all major species of iron and iron oxides. The scan rate was set at $2.0^{\circ}$ per min.

2.3.4. BET Method. Specific surface area of the nanofer ZVI was determined with the classic Brunauer-Emmer-Teller isotherm (BET) method. The BET isotherm was the basis for determining the extent of nitrogen adsorption on the particle surface. The nitrogen physiosorption with Coulter SA 3100 analyzer (Barrett-Joyner-Hanleda) was used in this study. The sample was placed on a glass tube and was exposed to nitrogen gas at precisely controlled pressures. As the pressure increased, the number of nitrogen molecules increased. The pressure at which adsorption equilibrium occurred was measured and the universal gas law was applied to determine the quantity of gas molecules adsorbed. The process continued until the point of bulk condensation of nitrogen. Following this, the reverse sequence of desorption occurred. The systematic sorption and desorption of nitrogen provided the important information related to surface area characteristic.

2.3.5. $\zeta$ Potential and Isoelectric Point. The surface charge of nanofer ZVI is often characterized by the zeta potential $(\zeta)$. Surface charge or zeta potential is the major factor determining the mobility of particles in an electrical field. The $\mathrm{pH}$ versus $\zeta$ potential diagram was employed to determine the isoelectric point (IEP) for the nanofer ZVI. The $\mathrm{pH}$ of the solution was adjusted with $2.0 \mathrm{~N} \mathrm{NaOH}$. An electromagnetic mixer was used to achieve rapid mixing. The titration began after the iron nanoparticles were suspended with deionized water for $30 \mathrm{~min}$ to allow the solution to reach equilibrium. The diagram of $\mathrm{pH}$ versus $\zeta$ yielded the IEP data.

2.4. Batch Kinetic Adsorption Experiments. Batch experiments were conducted to determine the kinetics of adsorption of heavy metals and dechlorination of TCE by nanofer ZVI. $0.01 \mathrm{M}$ of metals chloride was prepared, was sealed, and was left in the shaker for $24 \mathrm{hrs}(250 \mathrm{rpm})$. Nanofer ZVI and stock solution of metal chloride were added to $40 \mathrm{~mL}$ bottles. Following this, the (sample solution) bottles were closed and the caps with a Teflon liner sealed the bottles to prevent leakage. The head room in the bottle was kept to the minimum. The sample solution bottles were agitated on a mechanical shaker $(250 \mathrm{rpm})$ at $21^{\circ} \mathrm{C}$. Time was recorded for each bottle at the moment of adding the nZVI. Each bottle was assigned a time and a code. After regular time intervals, the nZVI particles were separated using vacuum filtration with $0.2 \mu \mathrm{m}$ filter (grade 42 Whatman). The $\mathrm{pH}$ and temperature were measured before and after adding the nZVI. The filtered solutions were immediately acidified 
and stored at $4^{\circ} \mathrm{C}$ prior to metal analyses. The Atomic absorption spectroscope (AAS, Perkin Elmer) was used for analysis of metals. Similar procedure was used to prepare the TCE solution samples. However, TCE concentration after reduction-oxidation was obtained by gas chromatography (GC Varian 3800).

2.5. Kinetic Experimental and Modeling. Batch kinetic experiment techniques were used to study the adsorption of metals and the degradation of TCE from contaminated water by nanofer ZVI. Both the liquid film diffusion model (LFDM) and the interparticles diffusion model were selected to describe the behavior of contaminants through the liquid phase (aqueous) to the solid phase surface of nanoparticle (nanofer ZVI). The main reason to select these two models is linked to the fact that adsorption between metal and nZVI is diffusion controlled. Besides the diffusion models, the Lagergren model was also used to describe the kinetics of both metals and TCE removal by nanofer ZVI. Qiu et al. [25] have provided a comprehensive discussion of several other related models.

\section{Results and Discussions}

3.1. Morphology and Surface Chemistry. Nanofer ZVI was characterized using images recorded by (XRD), (SEM), and (TEM). The specific surface area of the nanofer ZVI was determined by BET analysis. The division shown in the SEM images indicates $1 / 10$ of the range shown (i.e., $40 \mathrm{~nm}$ subdivision Figure 1(a)). Figures 1(a) and 1(b) show that the average particle size was $50 \mathrm{~nm}(20-100 \mathrm{~nm})$. The surface area ranged from 25 to $30 \mathrm{~m}^{2} \mathrm{~g}^{-1}$. The XRD analysis (Figure 3) indicated two distinct peaks at scanning angles corresponding to $45^{\circ}$ and $65^{\circ}$. The XRD index software (JCPDS) indicated that these peaks denote ferrite $(\alpha \mathrm{Fe}, 97.9 \%)$ and magnetite $\left(\mathrm{Fe}_{3} \mathrm{O}_{4}\right.$, $2.1 \%)$. The increase of pure iron (ferrite) is caused by the coating of nanofer ZVI with TEOS. However, Lenka et al. [7] found that the percentage of $\alpha$-Fe for uncoated ZVI 25 is $60 \%$ and is $70 \%$ for coated ZVI 25 . Further, Nurmi et al. [26] investigated the hydrogen reduction of iron oxides while Sun et al. [27] reduce $\mathrm{Fe}^{3+}$ by borohydride to form zerovalent nanoparticles. It was found that nZVI contains two phases. The $\alpha$-Fe was ranged from 30 to $70 \%$ and $\mathrm{Fe}_{3} \mathrm{O}_{4}$ was the surrounding oxide layer that ranged from 30 to $70 \%$. Broad peaks were observed by Sun et al. [27] in the TEM images for $\alpha$-Fe and $\mathrm{FeO}$. This contrasts with the slim peak for ferrite (98\%) in the image for the new nanofer ZVI (Figure 3). For fresh iron particles to be used for remediation of organic and inorganic form aqueous solutions, the fraction of the $\alpha$-Fe is expected to be higher than $80 \%$ to remain effective [19]. The higher percentage (98\%) of $\alpha$-Fe in nanofer ZVI clearly indicates that it is a very highly reactive adsorbent.

The surface area of the nanofer ZVI was determined to be $27.5 \pm 2 \mathrm{~m}^{2} \mathrm{~g}^{-1}$ by $\mathrm{N}_{2}$-BET analysis. However, the surface area of nanofer 25 (uncoated) was found to be $20 \pm$ $1 \mathrm{~m}^{2} \mathrm{~g}^{-1}$ [7]. It is believed that the increase in surface area between the (uncoated) nanofer 25 and the new nanofer ZVI is caused by the coating of particle which prevents agglomeration (Figures 4(a) and 4(b)). Unlike Figure 4(b) which clearly displays individual particles, Figure 4(a) does not show the existence of distinct particles. In Figure 2, the TEM image shows that nanofer ZVI exhibits a chain-like structure due to the inherent magnetic interaction between particles. The enlarged image (insert, Figure 2) also shows a dark area which is possibly the core of a single nanofer ZVI particle surrounded by a thin film of oxide shell. The thickness of the oxidizing shell (insert, Figure 2) based on the TEM software output indicated that the layer surrounding the core varied from 2 to $4 \mathrm{~nm}$.

Li et al. [17] investigated the characteristic of ion ZVI, coated by Pd. It was found that the average particle size is $70 \mathrm{~nm}$ and the surface area ranged from 30 to $35 \mathrm{~m}^{2} \mathrm{~g}^{-1}$. The oxide shell surrounding the core nanoparticle was less reactive due to metal coating.

Figures $1(\mathrm{c})$ and $1(\mathrm{~d})$ show corresponding image of SEMEDS elemental maps from agglomerate of the nanofer ZVI particles with both Cu II (Figure 1(c)) and TCE (Figure 1(d)). The particle exhibits strong intensity in the bulk of the agglomerate but depicts a clear increase in intensity at the edge region corresponding to the amorphous shell. The agglomerated image (Figures 1(a) and 1(b)) has much brighter light in the central of the amorphous region. Overlay of the elemental maps that are attached to the nanoparticle creating strong complex ligands. However, Weile [10] stated that the brighter colour in the SEM/EDS image represents amorphous oxide phase at the agglomerate surface and between the individual particles. In earlier studies, less focus was given to the chemical composition and microstructure of particle of the nanoparticle after use. The SEM/EDS (Table 3) technique employed in this study is able to unambiguously map out elemental distribution at a nanometer-scale spatial solution and thereby provides direct evidence of a core layered structure existing in these nZVI materials.

The effect of particle suitability and mobility was studied using $\zeta$ potential and the impact of $\mathrm{pH}$ on nanofer ZVI.

The isoelectric point (IEP) for the nanofer ZVI was found to be at $\mathrm{pH}$ of 4.3 (Figure 5). However, by increasing $\mathrm{pH}$ from 6.5 to $11, \mathrm{nZVI}$ displayed a $\zeta$ potential higher than $\pm 85 \mathrm{mV}$. It may be noted that this value of $\zeta$ potential is considered to be suitable for groundwater remediation. The nZVI with $\mathrm{pH}$ lower than 8.3 and $\zeta$ potential higher than $\pm 60 \mathrm{mV}$ is hence an excellent reagent and is attractive for the removal of aqueous contaminants [27]. Lenka et al. [7] reported similar results for IEP for the nZVI with a different film coating. However, they found that the $\zeta$ potential for uncoated nZVI 25 is below $\pm 30 \mathrm{mV}$ for the $\mathrm{pH}$ range of 6 to 10 . The uncoated nZVI was considered to be slightly suitable for groundwater treatment. Weile [10] detected that reduction-oxidation potential for PdZVI was $\pm 230 \mathrm{mV}$. Palladium in this case makes the ZVI more stable and mobile. However, the cost associated with the production of Pd-ZVI is considered to be a hurdle as it is much more expensive than TEOS.

3.2. Kinetics of $\mathrm{Pb}(\mathrm{II}), \mathrm{Cu}(\mathrm{II}), \mathrm{Cd}(\mathrm{II})$, and TCE Adsorption. To understand the metal affinities for nanofer ZVI as a function of time, adsorption edge experiments were 


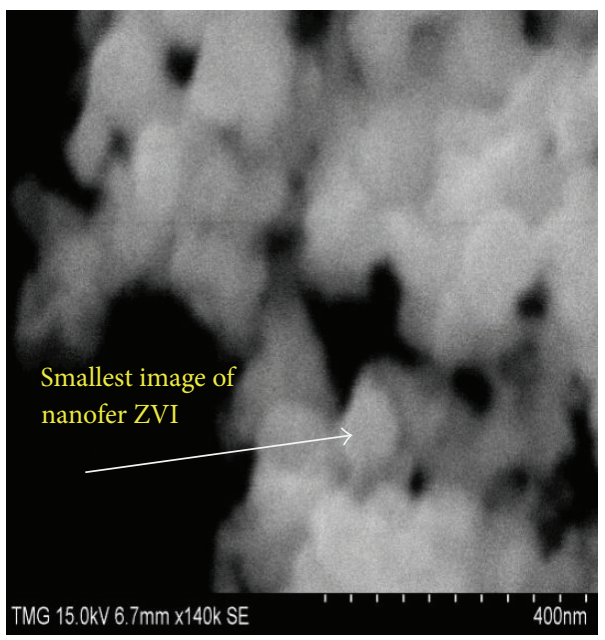

(a)

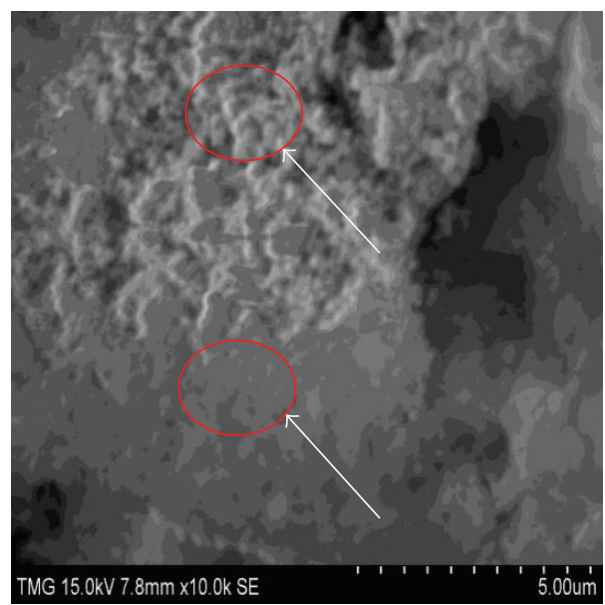

(c)

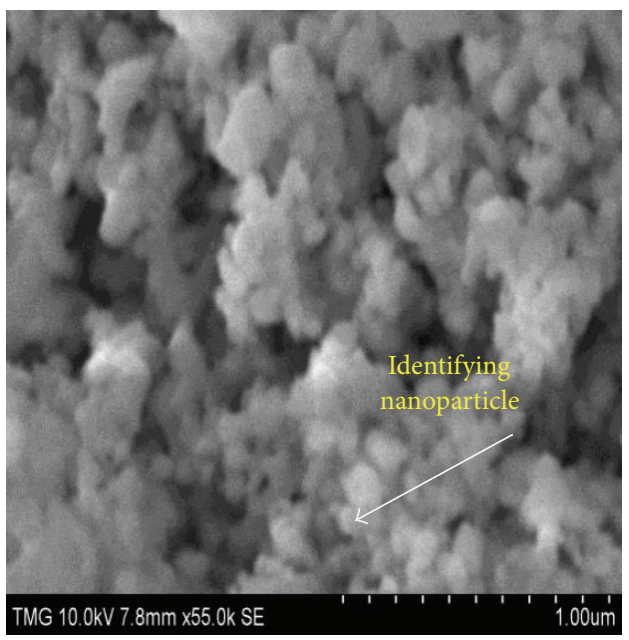

(b)

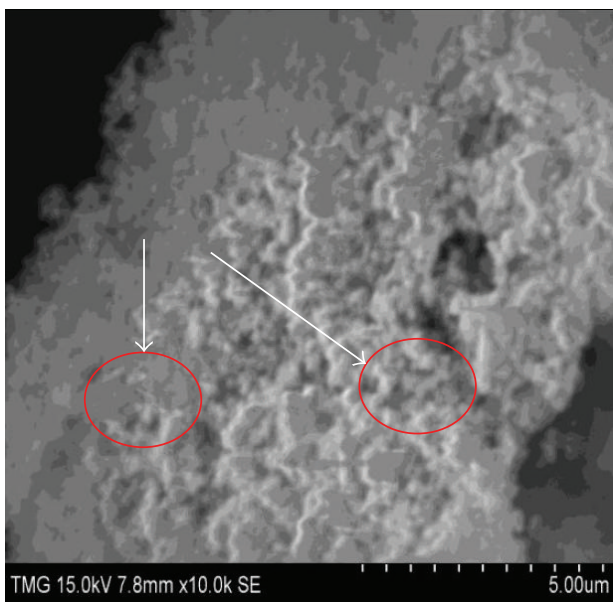

(d)

FIGURE 1: SEM images of nanofer ZVI (a) particle size in the range of $40 \mathrm{~nm}$. (b) Particle size in the range of $100 \mathrm{~nm}$. (c) Particle after oxidation of TCE. (d) Particle after Cu (II) adsorption. Arrow shows metal location.

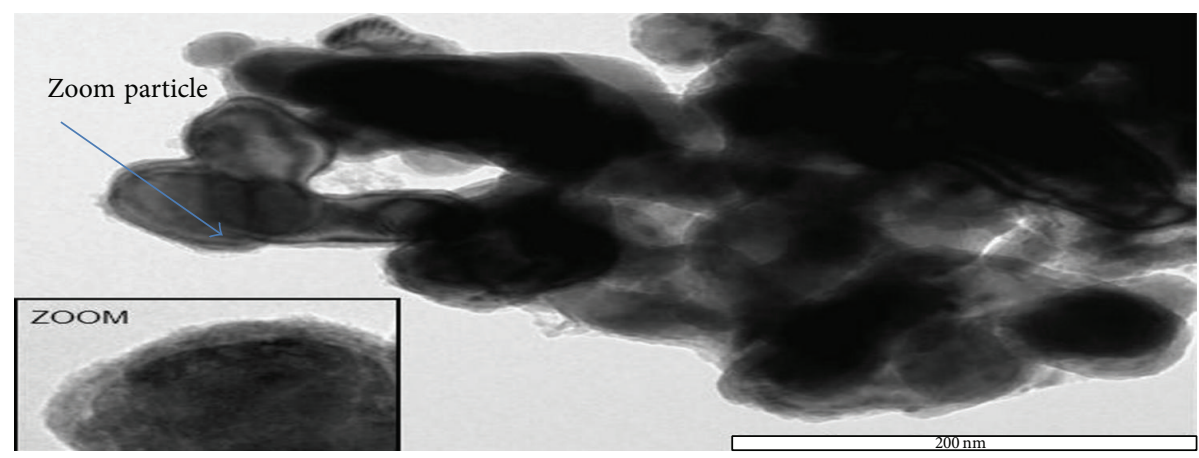

FIGURE 2: TEM images of nanofer ZVI with the oxide shell. Tip of arrow indicates zoom location.

performed (Figure 6). Preliminary studies indicated that the optimum nanofer ZVI dose was determined as $10 \mathrm{mg}$ per $40 \mathrm{~mL}$ test solution. Further, these studies also indicated that the optimum $\mathrm{pH}$ values were 5.5 for $\mathrm{Cu}$ (II), 4.8 for $\mathrm{Cd}$ (II), 4.5 for $\mathrm{Pb}$ (II), and 5.6 for TCE. Kinetic experiments also indicated that the adsorption of the metals and TCE is very rapid during the first 50 minutes of the initial step (Figure 6). This was followed by a much slower second step which was related to the solid state diffusion and the available surface area. Figure 6(a) shows the rapid and the slow steps for $\mathrm{Cd}$ 


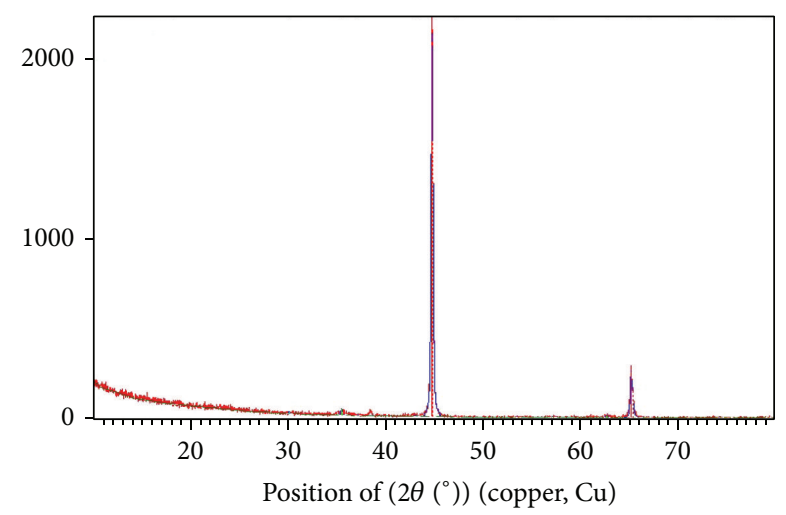

FIGURE 3: XRD nanofer ZVI of $\alpha$-Fe; the particle size: $50-100 \mathrm{~nm}$ and high content of iron in range of 70-90 wt.\% $(\lambda=1.5418 \AA, U=$ $40 \mathrm{Kv}$, and $I 30=30 \mathrm{~mA}$ ); composition: (green) $2.1 \%, \mathrm{FeO}_{3}$ and (red) $\alpha-\mathrm{Fe}, 97.9 \%$.

removal rate. The equilibrium solid phase concentration at time interval $\left(q_{t}\right)$ is calculated via the mass balance:

$$
q_{t}=\frac{V *\left(C_{0}-C_{S}\right)}{m}
$$

where $V$ is volume of contaminant (L), $m$ is the mass of nZVI $(\mathrm{mg}), C_{o}$ is the initial or control concentration (mole), and $C_{e}$ is the concentration after the sample is filtered at time interval (mole). The values of $q_{t}$ will be used to determine the mass transfer coefficient $K_{f}$.

In these studies, removal rates of $99.2 \%$ for $\mathrm{Cd}$ (II), $99.7 \%$ for $\mathrm{Pb}$ (II), $99.9 \%$ for $\mathrm{Cu}$ (II), and $99.4 \%$ for TCE were achieved in less than $180 \mathrm{~min}$. Further, no significant changes were observed in the removal of both metal ions and TCE after $8 \mathrm{hrs}$ of equilibration. During the first $10 \mathrm{~min}$, the rates of adsorption of $\mathrm{Cu}$ (II), $\mathrm{Pb}$ (II), and Cd (II) were $80 \%, 76 \%$, and $71 \%$, respectively. The adsorption of $\mathrm{Cu}$ (II) seems to be faster than the adsorptions of $\mathrm{Pb}$ (II) and Cd (II). This is probably related to their ionic hydrated radius and the electronegativity (Table 2). Chorstophi and Axe [28] have stated that the degree of affinities to adsorption sites is a function of site capacity and the equilibrium constant, which often coincide with the electronegativity of the corresponding metal ions. Schwertman and Taylor [29] reported that the affinities of metals ions for goethite in the crystal level also follow the order of $\mathrm{Cu}$ (II) $>\mathrm{Pb}$ (II) $>\mathrm{Cd}$ (II) as in the present case.

Although considerable studies have focused on the adsorption of TCE by ZVI, the mechanism of its degradation is not clearly understood and there is a general agreement that electron transfer at the absorbent is required for TCE degradation [29]. In the presence of oxygen, metallic iron gets oxidized and releases electrons which can be used in the reduction reaction of water. Depletion of oxygen can lead to an excess of positive charge in the solution causing the diffusion of chloride ions. Insoluble metal hydroxides can form and coat the external surface and thereby reduce the rate of TCE degradation. These specific results related to TCE degradation (Figure 6(d)) are in agreement with results of many previous studies [6,30-38].

SEM/EDS images (Figure 1) show the nanofer ZVI samples obtained before and after metal adsorption and TCE degradation. The expected effect of localized corrosion of metals (iron) due to the presence of chloride ion is not very evident from the images (Figures 1(c) and 1(d)) since the effect of localized corrosion can be noticed, only after a much longer period of metal exposure to oxidation $[2,15,29,39]$.

EDS techniques were used know the amount of metal adsorbed onto the nanoparticles. The results presented in Table 3 show that, during step 1, the rapid adsorption (weight \%) of $\mathrm{Cu}$ (II) was much more than that of $\mathrm{Pb}$ (II) and Cd (II). The result in agreement with the fact that $\mathrm{Cu}$ (II) has smaller ionic radius (Table 2) may allow it to be dipped into and attached to the outer surface of the nanofer ZVI.

\section{Sorption Kinetics}

Adsorption kinetics depends on the adsorbate-adsorbent interaction and system conditions. Two fundamental attributes of an adsorption process unit are its mechanism and reaction rate. Several studies have described the kinetics of metal adsorption on solid surfaces. Lagergren (1898) proposed the first order rate equation to describe the kinetic adsorption between the liquid-solid system based on solid capacity. Both the liquid film diffusion model and the homogenous solid diffusion model are generally used to describe the fundamental concept of kinetic adsorption controlled by liquid diffusion [40] or intraparticle diffusion [40].

4.1. First Order Kinetic Model. Equation (2) represents the Lagergren model (LM) which was used to determine the time interval required for ions [Cu (II), $\mathrm{Pb}$ (II), and $\mathrm{Cd}$ (II)] and molecules (TCE) to migrate from the liquid phase (solute) to the solid phase (nanofer ZVI). The kinetics data presented in Figure 6 was fitted with the following expression:

$$
\log \left(q_{e}-q_{t}\right)=\log q_{e}-\left(\frac{K_{1}}{2.303}\right) t .
$$

Here, $q_{e}$ and $q_{t}$ refer to the amount of metal ions adsorbed per unit weight of nanofer ZVI at equilibrium. The plots of $\log \left(q_{e}-q_{t}\right)$ versus $t$ are straight lines. The correlation coefficients for metals removal were determined. The corresponding value of $R^{2}$ for $\mathrm{Cu}$ (II) ions (insert, Figure 6(b)) was 0.99 . The $R^{2}$ values for $\mathrm{Pb}$ (II) and Cd (II) were respectively 0.97 and 0.95 . Further, for the initial concentration of $0.01 \mathrm{M}$ of $\mathrm{Pb}$ (II), Cd (II), and $\mathrm{Cu}$ (II) ions, the corresponding pseudo first order rate constants $\left(k_{1}\right)$ were determined to be $0.0137 \mathrm{~min}^{-1}, 0.0165 \mathrm{~min}^{-1}$, and $0.0187 \mathrm{~min}^{-1}$, respectively. These results show that, compared to other metals, $\mathrm{Cu}$ (II) has the fastest reaction rate. The results are in agreement with the earlier SEM/EDS analysis which indicated that a relatively much larger percentage of $\mathrm{Cu}$ (II) was present on the surface of the nanofer ZVI (Table 3). For TCE, the $R^{2}$ value was 0.96 and $K_{1}$ value was $0.0142 \mathrm{~min}^{-1}$. 


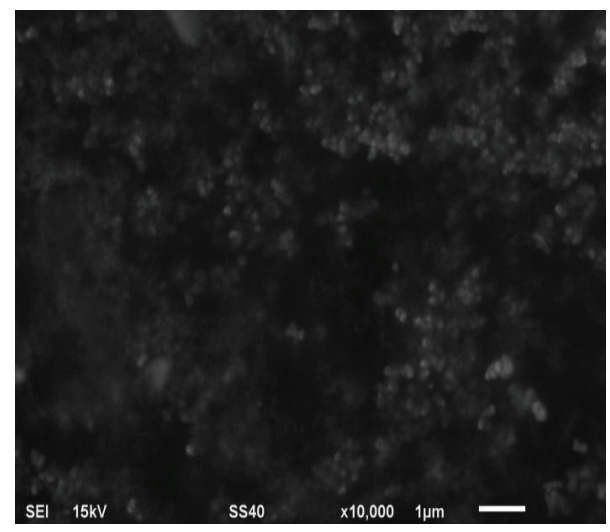

(a)

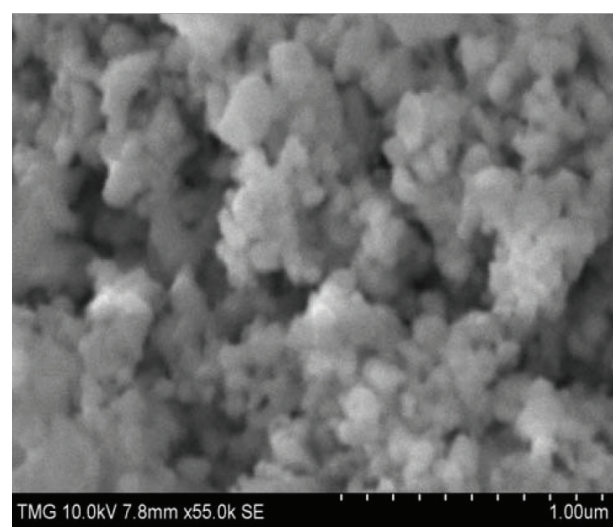

(b)

FIGURE 4: SEM images: (a) noncoated nanofer 25 taken after [7]. (b) Coated with silicon nanofer ZVI produced in TMG Lab, Concordia University.

TABLE 3: SEM/EDS analysis of kinetic experiments for single metal adsorption (step 1; rapid rate).

\begin{tabular}{|c|c|c|c|c|c|c|}
\hline \multirow{2}{*}{ Element } & \multicolumn{2}{|c|}{$\mathrm{Cu}$ (II) } & \multicolumn{2}{|c|}{$\mathrm{Pb}$ (II) } & \multicolumn{2}{|c|}{$\mathrm{Cd}$ (II) } \\
\hline & Weight $\%$ & Atomic\% & Weight $\%$ & Atomic\% & Weight $\%$ & Atomic\% \\
\hline $\mathrm{O}$ & 11.32 & 35.42 & 9.56 & 32.27 & 7.66 & 22.49 \\
\hline $\mathrm{Fe}$ & 82.17 & 59.93 & 86.53 & 67.36 & 91.98 & 77.39 \\
\hline $\mathrm{Cu}$ & 6.51 & 5.65 & & & & \\
\hline $\mathrm{Pb}$ & & & 3.91 & 0.37 & & \\
\hline $\mathrm{Cd}$ & & & & & 0.39 & 0.16 \\
\hline
\end{tabular}

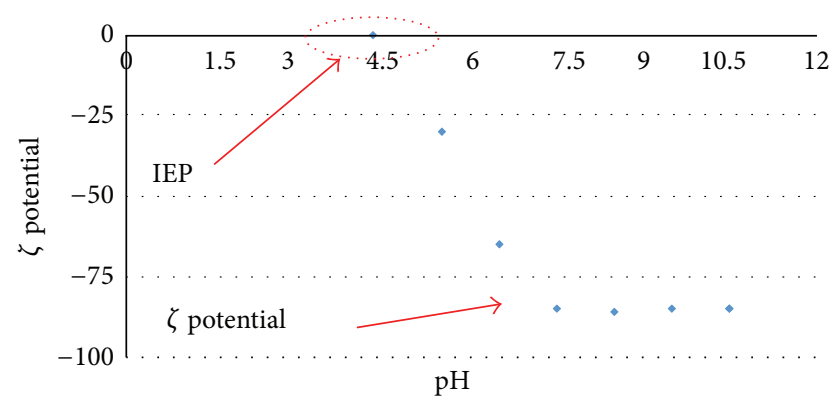

FIGURE 5: $\zeta$ potential as function of $\mathrm{pH}$ for nanofer ZVI [Isoelectric point (IEP)].

4.2. Adsorption Diffusion Model. The adsorption diffusion models involve film diffusion, intraparticle diffusion, and mass action [25, 41]. Liquid film diffusion model (LFDM) and intraparticle diffusion model (IDM) are the rate limiting steps used to describe kinetic adsorption [41]. However, these models are mainly developed to describe the process of film diffusion and intraparticle diffusion once the contaminants move from the liquid phase (aqueous solution) to the solid phase. In our case, nanofer ZVI denotes the solid phase. The liquid film diffusion model is based on the linear driving force law and is given by (2) [42]. Consider

$$
\frac{d q}{d t}=K_{f} \frac{A_{S}}{V_{p}}\left(C-C_{i}\right),
$$

where $V_{p}(d q / d t)$ demonstrates the rate of contaminant accumulation on the surface of nZVI. Here, $q$ represents the average contaminant concentration in the solid phase (nZVI), and $V_{p}$ is the volume of the particle. However, the rate of contaminant transfer across the liquid film is proportional to the surface area of the particle $(A)$ and the driving force that is controlled by concentration gradient $\left(C-C_{i}\right)$. Therefore, it is equal to $K_{f} A_{s}\left(C-C_{i}\right)$, where $K_{f}$ represents the film mass transfer coefficient.

The film diffusion mass transfer rate model ((3) and (4)) was developed earlier by Boyd et al. [40] and later refined by Qiu et al. [25]. Consider

$$
\begin{gathered}
\ln \left[1-\frac{q_{t}}{q_{e}}\right]=-R t, \\
R=\frac{3 D_{e}}{r_{0} \Delta r_{0} K_{f}} .
\end{gathered}
$$

The $R\left(\mathrm{~min}^{-1}\right)$ is the liquid film diffusion constant; De $\left(\mathrm{cm}^{2} \mathrm{~min}^{-1}\right)$ is the effective liquid film diffusion coefficient. $r_{0}(\mathrm{~cm})$ is the radius of particles (nanofer ZVI); $\Delta r_{0}(\mathrm{~cm})$ is the thickness of liquid film (which is estimated to be from 2 to $4 \mathrm{~nm}$ ); and $K_{f}$ is the equilibrium constant of adsorption defined in (3). By plotting $\left(1-q_{t} / q_{e}\right)$ versus $t$ (experimental data presented in Figure 6), a straight line with slope of $-R$ can be determined. Since film diffusion is the rate limiting step, the corrected film diffusion coefficient $D_{e}$ can be evaluated using (5). The values of liquid film diffusion constant $(R)$ and the effective liquid diffusion coefficient $\left(D_{e}\right)$ 


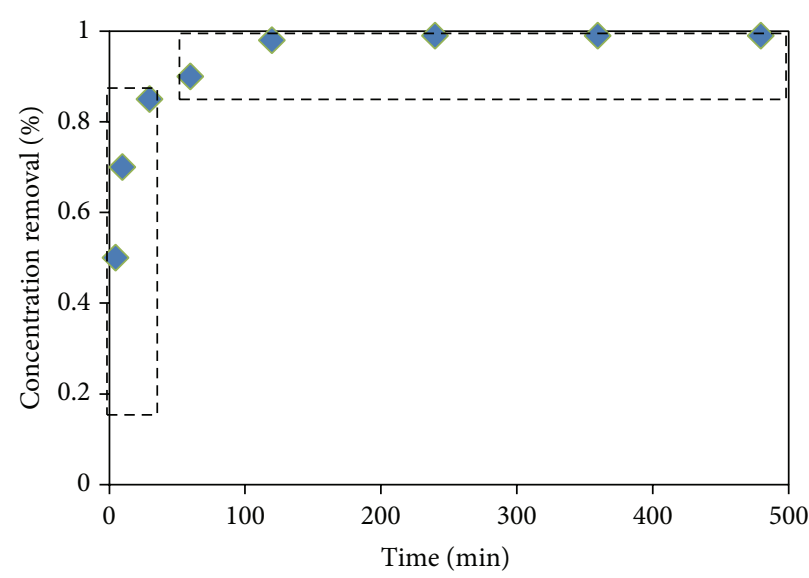

(a)

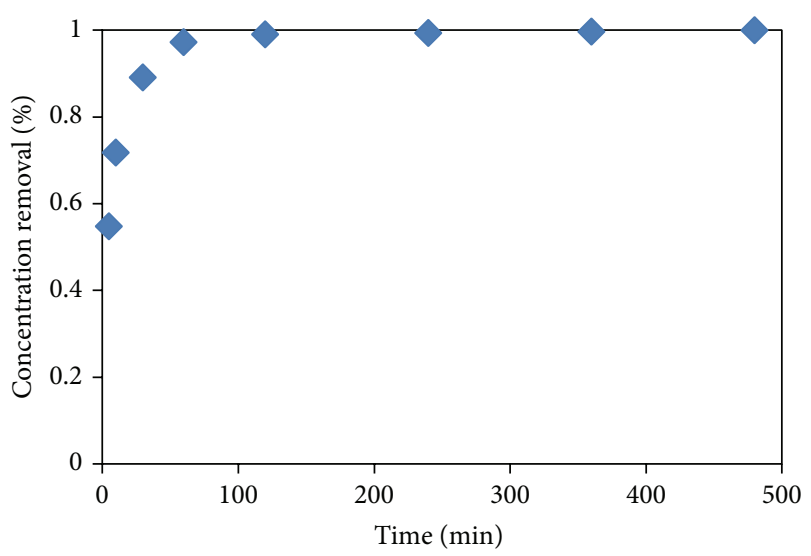

(c)

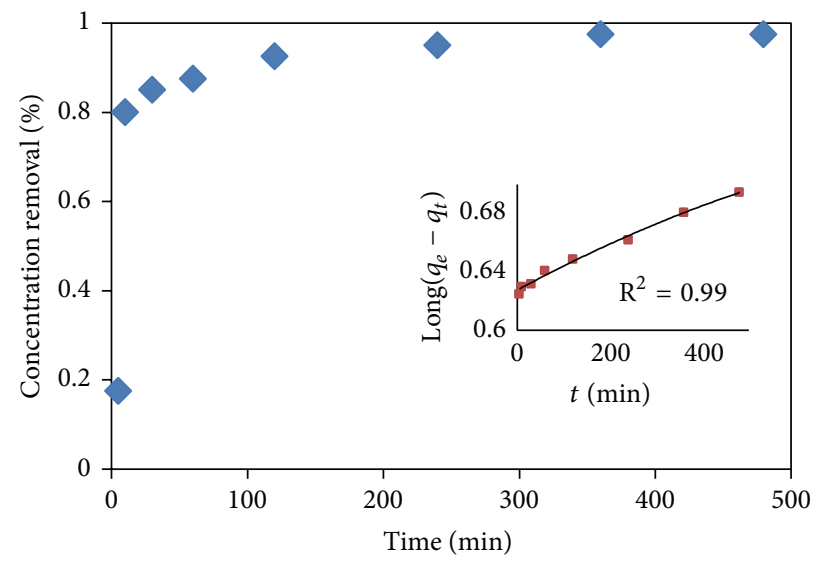

(b)

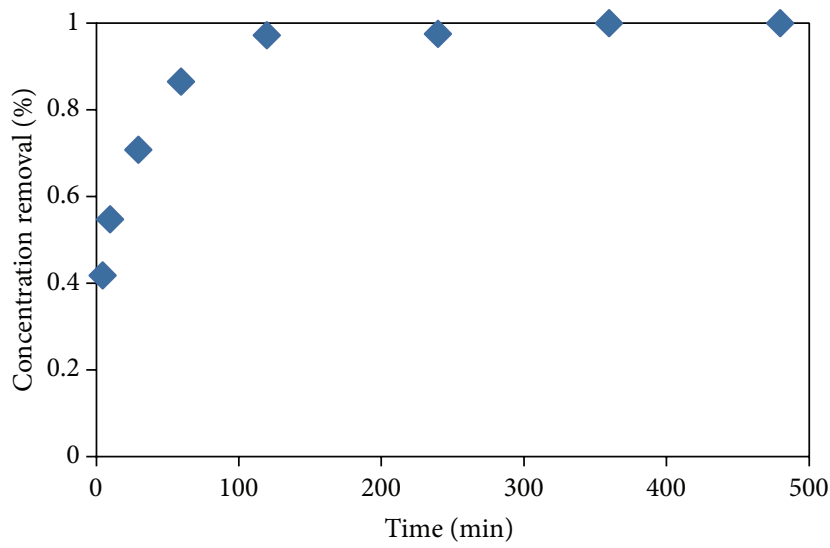

(d)

FIGURE 6: Kinetic adsorption of organic and inorganic contaminants by nanofer star ZVI; dose $10 \mathrm{mg}$; concentration $0.01 \mathrm{M}$; T: 20-22 $\mathrm{C}$; (a) $\mathrm{Cd}$ (II), (b) $\mathrm{Cu}$ (II), (c) Pb (II), and (d) TCE.

TABLE 4: Calculated parameters of both liquid film diffusion model and intraparticle diffusion model from kinetic data $\left(C_{0}=40 \mathrm{mg} / \mathrm{L}, T=\right.$ $\left.21-25^{\circ} \mathrm{C}\right)$.

\begin{tabular}{lcccc}
\hline Metals & \multicolumn{3}{c}{ Parameters } & $\begin{array}{c}k_{f} \\
\mathrm{~g} /(\mathrm{mg} \cdot \mathrm{min})\end{array}$ \\
\hline $\mathrm{Cu}(\mathrm{II})$ & $\mathrm{min}^{-1}$ & $\begin{array}{c}D_{e} \\
\mathrm{~cm}^{2} \mathrm{~min}^{-1}\end{array}$ & 2.97 & 0.083 \\
$\mathrm{~Pb}(\mathrm{II})$ & 0.0173 & 0.957 & 2.76 & 0.069 \\
$\mathrm{Cd}(\mathrm{II})$ & 0.0159 & 0.785 & 2.03 & 0.025 \\
\hline
\end{tabular}

are presented in Table 4. Meng, [41] successfully applied the liquid film diffusion model to predict breakthrough curve for the adsorption of phenol by a polymeric adsorption NDA1000 under different condition.

The intraparticle diffusion model (IDM) (6) is developed to describe the mass transfer in an amorphous and homogenous sphere [42]. Consider

$$
\frac{q_{e}}{q_{t}}=\left(6\left(\frac{D_{s}}{\pi R_{s} S^{2}}\right)\right)^{0.5} t^{0.5}
$$

where $D_{s}$ is the intraparticle diffusion coefficient; $R_{s}$ is the total particle radius. By plotting $q_{e} / q_{t}$ against $t^{0.5}$, the values of $D_{s}$ (Table 4 ) were determined for adsorption of three metals n nanofer ZVI. It can be concluded that as the particle size increases the adsorption rate decreases. The values of $D_{e}$ describe the movement of ions or particle in liquid film near the oxidizing layer which is considered the fast step. The values of $D_{s}$ describe the motion or movement of ions through the core shell of nZVI. The process is much slower due to resistivity and limited free service area [17, 31]. The LM and LFDM models are based on the first order kinetic model and the intraparticle diffusion models. Both these models 
are sequential steps (not independent entities). The two steps (two models) together yield factors such as $D_{s}, K_{f}$, and $D_{e}$.

Table 4 includes all parameters of (3), (4), (5), and (6). The film diffusion coefficient $D_{e}$ for the $\mathrm{Cu}$ (II) ion seems to be higher than that for $\mathrm{Pb}$ (II) and $\mathrm{Cd}$ (II). As mentioned earlier, the metal ions adsorption is often described as a twostep mechanism adsorption [43]. The first step represents the rapid metal adsorption occurring due to the diffusion of metal ions from the liquid phase to the external solid phase (nanofer ZVI). In the present study, the time interval for the initial fast step is estimated to be about 10 minutes. Subsequently, a slow step results in the intraparticle diffusion which controls the adsorption rate and finally the metal adsorption reaches the equilibrium. Chiron et al. [44] presented similar results for the adsorption of $\mathrm{Cu}$ (II) and $\mathrm{Pb}$ (II) from aqueous solutions by activated carbon and grafted silica.

The film mass transfer coefficients $K_{f}$ (Table 4) represent the rapid step. It appears that the initial rate of $\mathrm{Cu}$ (II) diffusion is significantly higher than that for $\mathrm{Pb}$ (II) and $\mathrm{Cd}$ (II) ions. The metal concentrations were measured by AA to the nearest $0.1 \mathrm{mg} / \mathrm{L}$. The overall error of concentration measurement is estimated to vary typically from 1 to $3 \%$.

Admittedly, there is a slight ambiguity in interpreting results of Figure 6(b) and Figure 6(c). For instance, Cu II reaches $80 \%$ adsorption in less than 5 min compared to $\mathrm{Pb}$ II which attains $80 \%$ adsorption in $15 \mathrm{~min}$, indicating that $\mathrm{Cu}$ II adsorption rate is faster in this range. However for $99 \%$ removal, $\mathrm{Pb}$ II is adsorbed faster. On the other hand, the data (Table 4) for effective liquid film diffusion coefficient $\left(D_{e}\right.$, fast step) and intraparticle diffusion coefficient $\left(D_{s}\right.$, slow step) predict that the $\mathrm{Cu}$ II has the highest adsorption rate while $\mathrm{Cd}$ II has the lowest adsorption rate in both the fast and slow steps and hence the results (Table 4) are unambiguous. The results of these models may contribute to understanding the overall kinetics of adsorption mechanism, which was discussed earlier. The rapid step depends on external diffusion. In earlier studies, it is noted that the slow step (internal diffusion) is mainly controlled by intraparticle diffusion and probably this is independent of the particle agglomeration as well as individual metal characteristics [43, 44].

\section{Conclusions}

Batch studies indicated that the new and innovative adsorbent nanofer ZVI was capable of removing contaminant such as heavy metals [Cu (II), Pb (II), and Cd (II)] as well as organic [TCE] from polluted water. The comprehensive physical and chemical characteristics of adsorbent (nanofer ZVI) before and after the experiment were determined using images captured by SEM, EDS, and TEM. Nanofer ZVI with $98 \%$ of $\alpha$-Fe is very highly reactive and hence acts as an effective adsorbent that can remove contaminants from polluted water. The batch kinetic test data confirmed that almost all (99\%) of the heavy metals such as (Cu (II), Pb (II), and Cd (II)) can be adsorbed. In case of TCE, the nanofer ZVI got oxidized and released electrons which reduce the reaction of water. Depletion of oxygen led to an excess of positive charge in the solution causing the diffusion of chloride ions to the surface of nanofer ZVI. The results also indicated that nanofer ZVI degrades TCE almost completely. Batch kinetic adsorption and EDS analysis indicated that the adsorption of $\mathrm{Cu}$ (II) was relatively higher compared to the adsorption of $\mathrm{Pb}$ (II) and $\mathrm{Cd}$ (II). Both the film diffusion model and the intraparticle diffusion model confirmed that, compared to the $\mathrm{Pb}$ (II) and $\mathrm{Cd}$ (II), the diffusion of $\mathrm{Cu}$ (II) was much faster. The models also implied that the metals transfer to nanofer ZVI was achieved in two stages. The first stage involved the rapid step which was controlled by liquid diffusion. The second stage involved the slow step which was controlled by intraparticle diffusion.

\section{Conflict of Interests}

The authors declare that there is no conflict of interests regarding the publication of this paper.

\section{Acknowledgments}

The support of the NANOIRON ltd (Czech Republic) for supplying the nanofer ZVI, the technical assistance of TMG group for the use for SEM/EDS and XRD, and the accessibility to environmental engineering facilities at Concordia University (Montreal) are thankfully acknowledged.

\section{References}

[1] C. Mace, S. Desrocher, F. Gheorghiu et al., "Nanotechnology and groundwater remediation: step forward in technology understanding," Remediation Journal, vol. 16, no. 2, pp. 23-33, 2006.

[2] N. C. Mueller, J. Braun, J. Bruns et al., "Application of nanoscale zero valent iron (NZVI) for groundwater remediation in Europe," Environmental Science and Pollution Research, vol. 19, no. 2, pp. 550-558, 2012.

[3] C. R. Keenan and D. L. Sedlak, "Factors affecting the yield of oxidants from the reaction of nanoparticulate zero-valent iron and oxygen," Environmental Science and Technology, vol. 42, no. 4, pp. 1262-1267, 2008.

[4] D. M. Cwiertny, S. J. Bransfield, and A. L. Roberts, "Influence of the oxidizing species on the reactivity of iron-based bimetallic reductants," Environmental Science and Technology, vol. 41, no. 10, pp. 3734-3740, 2007.

[5] Y. Liu, S. A. Majetich, R. D. Tilton, D. S. Sholl, and G. V. Lowry, "TCE dechlorination rates, pathways, and efficiency of nanoscale iron particles with different properties," Environmental Science and Technology, vol. 39, no. 5, pp. 1338-1345, 2005.

[6] G. V. Lowry and K. M. Johnson, "Congener-specific dechlorination of dissolved PCBs by microscale and nanoscale zerovalent iron in a water/methanol solution," Environmental Science and Technology, vol. 38, no. 19, pp. 5208-5216, 2004.

[7] H. Lenka, J. Petra, and S. Zdenek, "Nanoscale zero valent iron coating for subsurface application," in Proceedings of the 4th International Conference, vol. 10, pp. 23-25, Brno, Czech Republic, 2012.

[8] T. Raychoudhury, G. Naja, and S. Ghoshal, "Assessment of transport of two polyelectrolyte-stabilized zero-valent iron 
nanoparticles in porous media," Journal of Contaminant Hydrology, vol. 118, no. 3-4, pp. 143-151, 2010.

[9] C. M. Cirtiu, T. Raychoudhury, S. Ghoshal, and A. Moores, "Systematic comparison of the size, surface characteristics and colloidal stability of zero valent iron nanoparticles pre- and post-grafted with common polymers," Colloids and Surfaces A, vol. 390, no. 1-3, pp. 95-104, 2011.

[10] Y. Weile, Iron-based nanoparticles: investigating, the nanostructure, surface chemistry, and reaction with environmental contaminants [Dissertation], Lehigh University, 2011.

[11] B. Karn, T. Kuiken, and M. Otto, "Nanotechnology and in situ remediation: a review of the benefits and potential risks," Environmental Health Perspectives, vol. 117, no. 12, pp. 1823-1831, 2009.

[12] U.S. EPA, "Nanotechnology white paper," EPA 100/B-07/001, Environmental Protection Agency, Washington, DC, USA, 2007.

[13] B. Nowack, "Pollution prevention and treatment using nanotechnology," in Nanotechnology, H. Krug, Ed., vol. 2 of Environmental Aspects, pp. 1-15, Wiley-VCH, Weinheim, Germany, 2008.

[14] V. Stone, B. Nowack, A. Baun et al., "Nanomaterials for environmental studies: classification, reference material issues, and strategies for physico-chemical characterisation," Science of the Total Environment, vol. 408, no. 7, pp. 1745-1754, 2010.

[15] N. C. Mueller and B. Nowack, "Nanoparticles for remediation: solving big problems with little particles," Elements, vol. 6, no. 6, pp. 395-400, 2010.

[16] F. Greenlee, T. Jessica, R. Amro, and J. Shaw, "Kinetics of zero valent iron nanoparticle oxidation in oxygenated water," Environment Science Technology, vol. 46, no. 23, pp. 1291312920, 2012.

[17] X.-Q. Li, D. W. Elliott, and W.-X. Zhang, "Zero-valent iron nanoparticles for abatement of environmental pollutants: materials and engineering aspects," Critical Reviews in Solid State and Materials Sciences, vol. 31, no. 4, pp. 111-122, 2006.

[18] L. D. David, Handbook of Chemistry and Physics, CRC, Boca Raton, Fla, USA, 78th edition, 1998.

[19] M. Cornell and U. Schwertmann, The Iron Oxides: Structure, Properties, Reactions, Occurrences, and Uses, Wiley-VCH, Weinheim, Germany, 2nd edition, 2003.

[20] X.-Q. Li and W.-X. Zhang, "Sequestration of metal cations with zerovalent iron nanoparticles: a study with high resolution $\mathrm{X}$ ray photoelectron spectroscopy (HR-XPS)," Journal of Physical Chemistry C, vol. 111, no. 19, pp. 6939-6946, 2007.

[21] D. O'Carroll, B. Sleep, M. Krol, H. Boparai, and C. Kocur, "Nanoscale zero valent iron and bimetallic particles for contaminated site remediation," Advances in Water Resources, vol. 51, pp. 104-122, 2013.

[22] R. Rangsivek and M. R. Jekel, "Removal of dissolved metals by zero-valent iron (ZVI): kinetics, equilibria, processes and implications for stormwater runoff treatment," Water Research, vol. 39, no. 17, pp. 4153-4163, 2005.

[23] A. Ayob, I. Norli, T. Tjoon, and A. Ahmed, "Immobilization of $\mathrm{Cu}^{2+}$ using stabilized nano zero valent iron particles in contaminated aqueous solutions," Environment Protection Engineering, vol. 38, no. 3, pp. 119-131, 2012.

[24] A. Saberi, "Comparison of $\mathrm{Pb}$ removal efficiency by zero valent iron nanoparticles and Ni/Fe bimetallic nanoparticles'Iranica," Journal of Energy and Environment, vol. 3, no. 2, pp. 189-196, 2012.
[25] H. Qiu, L. Lv, B.-C. Pan, Q.-J. Zhang, W.-M. Zhang, and Q.-X. Zhang, "Critical review in adsorption kinetic models," Journal of Zhejiang University A, vol. 10, no. 5, pp. 716-724, 2009.

[26] J. T. Nurmi, P. G. Tratnyek, V. Sarathy et al., "Characterization and properties of metallic iron nanoparticles: spectroscopy, electrochemistry, and kinetics," Environmental Science and Technology, vol. 39, no. 5, pp. 1221-1230, 2005.

[27] Y. Sun, X. Li, X. J. Cao, W. Zhang, and H. P. Wang, "Characterization of zero-valent iron nanoparticles," Advance Colloid Interface Sciences, vol. 120, pp. 47-56, 2006.

[28] C. A. Christophi and L. Axe, "Competition of $\mathrm{Cd}, \mathrm{Cu}$, and $\mathrm{Pb}$ adsorption on goethite," Journal of Environmental Engineering, vol. 126, no. 1, pp. 66-74, 1999.

[29] U. Schwertman and R. M. Taylor, "Iron oxides," in Minerals in Soil Environments, SSSA Book Series No. 1, pp. 379-427, Soil Science of America, Madison, Wis, USA, 2nd edition, 1989.

[30] J. Gotpagar, S. Lyuksyutov, R. Cohn, E. Grulke, and D. Bhattacharyya, "Reductive dehalogenation of trichloroethylene with zero-valent iron: surface profiling microscopy and rate enhancement studies," Langmuir, vol. 15, no. 24, pp. 8412-8420, 1999.

[31] M. Mohapatra, I. Mohapatra, P. Singh, S. Anand, and B. Mishra, "A comparative study of $\mathrm{Pb}$ (II) II, Cu II, Co II, Cd (II) adsorption from single and binary aqueous solution on additive assisted nano-structed goethite," International Journal of Engineering, Science and Technology, vol. 2, no. 8, pp. 89-103, 2010.

[32] M. Nadeem, M. Shabbir, M. A. Abdullah, S. S. Shah, and G. McKay, "Sorption of cadmium from aqueous solution by surfactant-modified carbon adsorbents," Chemical Engineering Journal, vol. 148, no. 2-3, pp. 365-370, 2009.

[33] E.-S. Z. El-Ashtoukhy, N. K. Amin, and O. Abdelwahab, "Removal of lead (II) and copper (II) from aqueous solution using pomegranate peel as a new adsorbent," Desalination, vol. 223, no. 1-3, pp. 162-173, 2008.

[34] E. Pehlivan and T. Altun, "The study of various parameters affecting the ion exchange of $\mathrm{Cu}^{2+}, \mathrm{Zn}^{2+}, \mathrm{Ni}^{2+}, \mathrm{Cd}^{2+}$, and $\mathrm{Pb}^{2+}$ from aqueous solution on Dowex 50W synthetic resin," Journal of Hazardous Materials, vol. 134, no. 1-3, pp. 149-156, 2006.

[35] A. Saeed, M. W. Akhter, and M. Iqbal, "Removal and recovery of heavy metals from aqueous solution using papaya wood as a new biosorbent," Separation and Purification Technology, vol. 45 , no. 1, pp. 25-31, 2005.

[36] S.-F. Cheng and S.-C. Wu, "The enhancement methods for the degradation of TCE by zero-valent metals," Chemosphere, vol. 41, no. 8, pp. 1263-1270, 2000.

[37] M. M. Benjamin and J. O. Leckie, "Multiple-site adsorption of $\mathrm{Cd}, \mathrm{Cu}, \mathrm{Zn}$, and $\mathrm{Pb}$ on amorphous iron oxyhydroxide," Journal of Colloid And Interface Science, vol. 79, no. 1, pp. 209-221, 1981.

[38] C.-B. Wang and W.-X. Zhang, "Synthesizing nanoscale iron particles for rapid and complete dechlorination of TCE and PCBs," Environmental Science and Technology, vol. 31, no. 7, pp. 2154-2156, 1997.

[39] H.-H. Strehblow, "Breakdown of passivity and localized corrosion: theoretical concepts and fundamental experimental results," Werkstoffe und Korrosion, vol. 35, no. 10, pp. 437-448, 1984.

[40] G. E. Boyd, A. W. Adamson, and L. S. Myers Jr., "The exchange adsorption of ions from aqueous solutions by organic zeolites. II. Kinetics," Journal of the American Chemical Society, vol. 69, no. 11, pp. 2836-2848, 1947. 
[41] W. Meng, Study on a mathematical model in predicting breakthrough curves of fixed-bed Adsorption onto resin adsorbent [M.S. thesis], Nanjing University, Nanjing, China, 2005.

[42] O. Cooney, Adsorption Design for Wastewater Treatment, Lewis Publishers, Boca Raton, Fla, USA, 1999.

[43] A. Wilczak and T. M. Keinath, "Kinetics of sorption and desorption of copper(II) and lead(II) on activated carbon," Water Environment Research, vol. 65, no. 3, pp. 238-244, 1993.

[44] N. Chiron, R. Guilet, and E. Deydier, "Adsorption of $\mathrm{Cu}(\mathrm{II})$ and $\mathrm{Pb}(\mathrm{II})$ onto a grafted silica: Isotherms and kinetic models," Water Research, vol. 37, no. 13, pp. 3079-3086, 2003. 

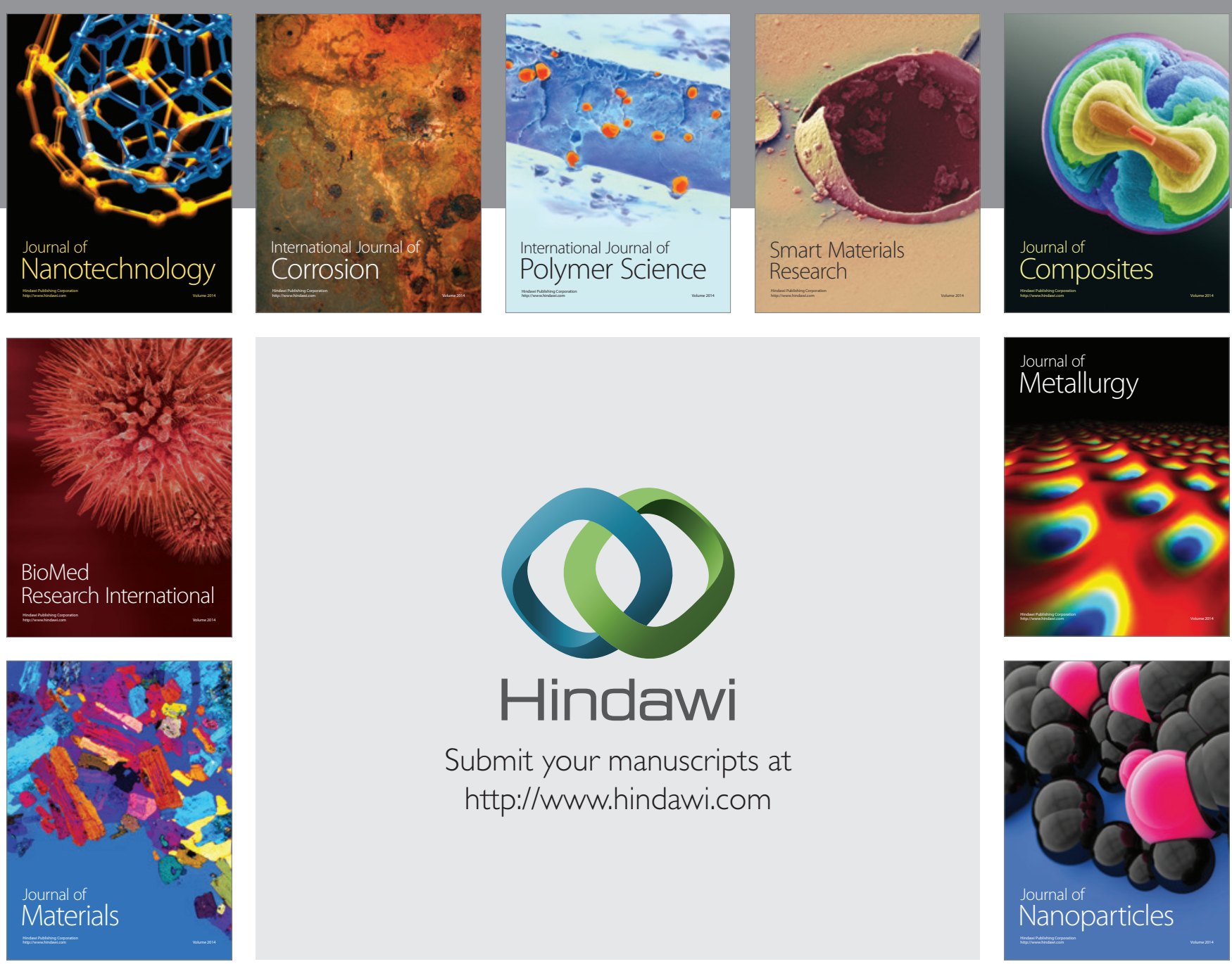

Submit your manuscripts at http://www.hindawi.com
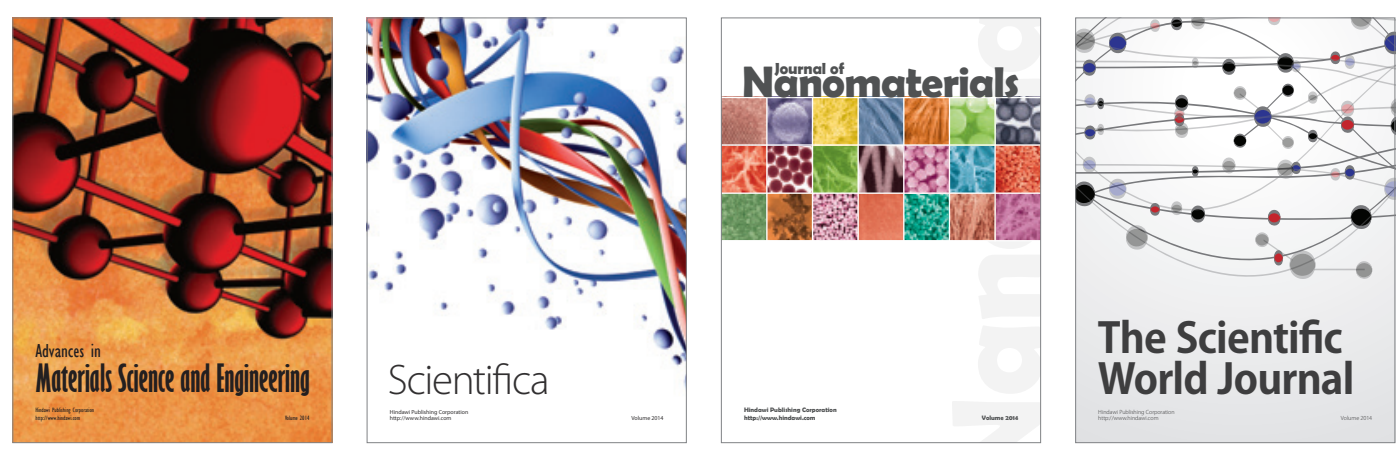

\section{The Scientific World Journal}
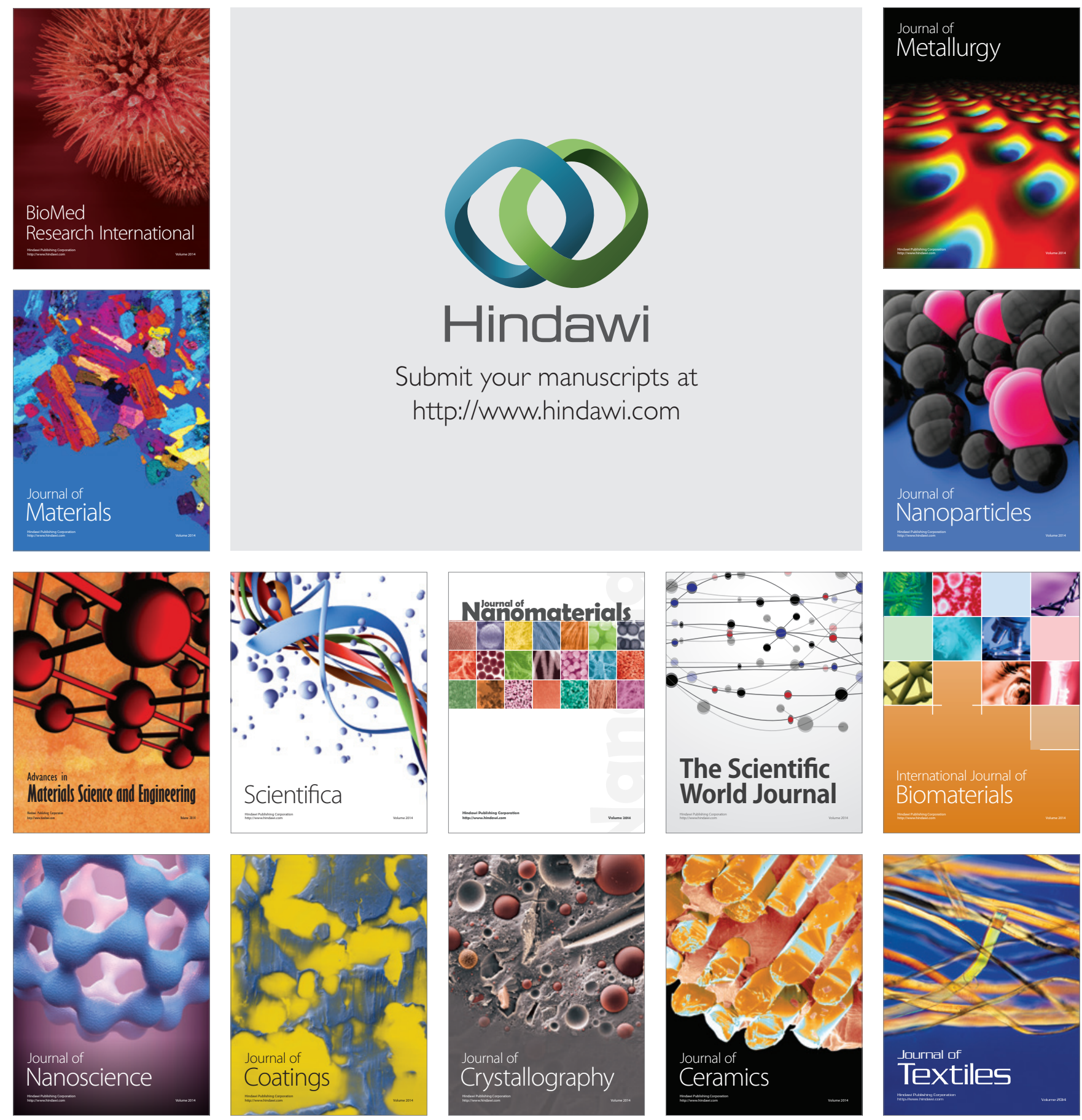